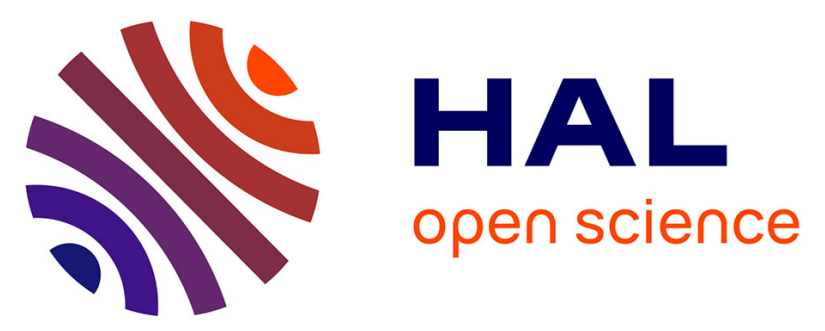

\title{
Impact of obesity on bone mass throughout adult life: Influence of gender and severity of obesity
}

Laurent Maïmoun, Thibault Mura, Elodie Leprieur, Antoine Avignon, Denis

Mariano-Goulart, Ariane Sultan

\section{- To cite this version:}

Laurent Maïmoun, Thibault Mura, Elodie Leprieur, Antoine Avignon, Denis Mariano-Goulart, et al.. Impact of obesity on bone mass throughout adult life: Influence of gender and severity of obesity. BONE, 2016, 90, pp.23 - 30. 10.1016/j.bone.2015.11.020 . hal-01800534

\section{HAL Id: hal-01800534 \\ https://hal.umontpellier.fr/hal-01800534}

Submitted on 6 Dec 2019

HAL is a multi-disciplinary open access archive for the deposit and dissemination of scientific research documents, whether they are published or not. The documents may come from teaching and research institutions in France or abroad, or from public or private research centers.
L'archive ouverte pluridisciplinaire HAL, est destinée au dépôt et à la diffusion de documents scientifiques de niveau recherche, publiés ou non, émanant des établissements d'enseignement et de recherche français ou étrangers, des laboratoires publics ou privés. 


\title{
Impact of obesity on bone mass throughout adult life: Influence of gender and severity of obesity
}

\author{
Laurent Maïmoun $^{\mathrm{a}, \mathrm{b}, *}$, Thibault Mura $^{\mathrm{c}}$, Elodie Leprieur ${ }^{\mathrm{d}}$, Antoine Avignon ${ }^{\mathrm{b}, \mathrm{d}}$, \\ Denis Mariano-Goulart ${ }^{\mathrm{a}, \mathrm{b}}$, Ariane Sultan ${ }^{\mathrm{b}, \mathrm{d}}$ \\ a Département de Médecine Nucléaire, CHRU Montpellier, Montpellier, France \\ b U1046 INSERM, UMR9214 CNRS, Physiologie et Médecine Expérimentale du Cœur et des Muscles, University of Montpellier, CHRU Montpellier, France \\ ' Département d'Information Médicale, CHRU Montpellier, Montpellier, France \\ d Département Endocrinologie, Nutrition, Diabète, Equipe Nutrition, Diabète, CHRU Montpellier, Montpellier, France
}

Keywords:

Obesity

Areal bone mineral density

Osteoporosis

Men and women

\begin{abstract}
A B S T R A C T
Background: Obesity improves areal bone mineral density (aBMD). However, it is unknown whether gender, ageing or the severity of obesity could modulate this effect and whether different bone sites are similarly affected. Objective: The aim of this observational study was to model the aBMD variation in obese patients from peak bone period to old age according to gender, bone localisation and severity of obesity.

Subjects and methods: Five hundred and four obese patients ( 363 women, 72\%) with a mean BMI of $38.5 \pm$ $6.0 \mathrm{~kg} / \mathrm{m}^{2}$, aged from 18.1 to 81.9 years (mean age $49.6 \pm 14.6$ years) were recruited. The whole body (WB), hip, lumbar spine (L1-L4) and one-third radius aBMDs were determined using dual-energy X-ray absorptiometry (DXA).

Results: Z-scores were significantly increased, above the age- and gender-related mean, both for women and men at WB (respectively 0.79 SD and 0.32 SD), hip (1.09 SD and 1.06 SD), one-third radius (1.70 SD and 0.45 SD) and L1-L4 levels ( 0.86 SD for women only). The improvement of Z-scores was significantly more marked in women compared to men at all bone sites, hip excepted. Furthermore, differences compared with normal values were significantly accentuated by ageing, without noticeable gender effect. In women, regardless of BMI and bone site, Z-scores were higher than normal values, this difference being most marked at WB, L1-L4 and hip levels for obese patients with a BMI above $40 \mathrm{~kg} / \mathrm{m}^{2}$. Lean mass, but not fat mass, was independently associated with aBMD in men and women.

Conclusion: This study demonstrated for the first time that obesity induces an improvement of aBMD, which is modulated by bone site location, severity of obesity, age and gender. The accentuation of peak bone mass combined with a reduction of bone loss rate with ageing may explain why obese patients present a lower prevalence of osteoporosis.
\end{abstract}

\section{Introduction}

Obesity is a major public health concern. In fact, more than $50 \%$ of the United State adult population are overweight or obese, and it is estimated that this rate would reach $75 \%$ by 2020 [1]. In Europe, the prevalence of overweight and obesity in individuals older than 50 years is $49.8 \%$ and $13.3 \%$ for men and $36.1 \%$ and $13.5 \%$ for women, respectively, however with substantial variation across countries [2]. Both overweight and obesity are associated with chronic health conditions, such as type 2 diabetes, high blood cholesterol, and hypertension [2]. Despite their physical inactivity, several studies have demonstrated

* Corresponding author at: Département de Biophysique, Université de Montpellier, Service de Médecine Nucléaire, Hopital Lapeyronie, 371, avenue du doyen Gaston Giraud, 34295 Montpellier cedex 5, France.

E-mail address: 1-maimoun@chu-montpellier.fr (L. Maïmoun). that obese patients present higher areal bone mineral density (aBMD) than normal-weight control subjects [3-7]. Indeed, increased body weight or body mass index (BMI) is associated with higher aBMD and reduced fracture risk [8].

Nevertheless, the effect of obesity on bone mass throughout adult life is not well described, although it is an important issue as both prevalence of obesity and life expectancy are increasing. Indeed, most studies included specific categories of patients: premenopausal $[3,4,6]$ or postmenopausal women [5-7], young men [6,9] or both men and women $[3,6]$ and results suggested that the effect of obesity on bone mass could be modulated by gender and/or ageing $[6,10]$. To our knowledge, only one recent study has simultaneously included young (25-40 years old) and older (55-75 years old) men and women, with or without obesity. The results showed a more important effect of obesity on aBMD of older adults compared to younger, without any gender effect [6]. However, the analysis in two subgroups (i.e., young and older) 
did not allow for a global evaluation of aBMD variation throughout adult life [6].

Therefore, the aim of this study was to analyse the relationship between aBMD and obesity, at different bone sites, throughout the adult life of men and women with different severity of obesity. We also investigated other factors related to body composition in order to identify those potentially implicated in the "bone adaptation" at weight-bearing and non-weight-bearing skeletal sites.

\section{Subjects and methods}

This observational study was based on the evaluation of obese patients (BMI $\geq 30 \mathrm{~kg} / \mathrm{m}^{2}$ ), recruited in the Nutrition Clinic of the University Hospital of Montpellier, France, between December 2012 and February 2014 where they had been referred for metabolic and physical assessment of their obesity. The majority of patients had a long-standing history of obesity (more than 5 years) and was not taking any calcium or vitamin D supplementation. None of the included patients had undergone bariatric surgery or presented with a known bone disease. Patients with prosthesis or a body weight $>190 \mathrm{~kg}$ were excluded from the study due to the limitations of the densitometry device. Medical history and menopausal status, when relevant, were obtained by questionnaires. Moreover, histories of smoking status, diabetes mellitus, as well as current medications were recorded. Height and weight were measured wearing light clothing and no shoes; BMI was calculated as weight in $\mathrm{kg}$ divided by the square of height in metres $\left(\mathrm{kg} / \mathrm{m}^{2}\right)$. Waist circumference was recorded to the nearest $0.1 \mathrm{~cm}$ midway between the last rib and the crest of the ileum using a non-stretch tape measure. Each patient was categorized in a group according to the grade of obesity using the World Health Organization (WHO) definition [11]: class I (BMI $30-34.9 \mathrm{~kg} / \mathrm{m}^{2}$ ), class II (BMI 35-39.9 kg/m²), or class III (BMI $\left.\geq 40 \mathrm{~kg} / \mathrm{m}^{2}\right)$.

\subsection{Patients' consent}

All participants gave written informed consent. The study was performed according to the principles of the Declaration of Helsinki and was approved by the local ethics committee (CPP Sud-Méditerranée IV, Montpellier, France). All patients were entered into a registry with data collected during their hospitalization, including anthropometric, clinical and biological information ( $\left.\mathrm{N}^{\circ} \mathrm{DC}-2009-1052\right)$.

\subsection{Laboratory procedures}

Blood was drawn in the morning after an 8-hour overnight fast. Plasma calcium and phosphorus levels were assayed using Cobas 6000 (Roche Diagnostic, Mannheim, Germany).

\subsection{Bone mineral density, body fat and lean mass}

aBMD $\left(\mathrm{g} / \mathrm{cm}^{2}\right)$ at the whole body (WB) as well as at specific bone sites: the antero-posterior lumbar spine (L1-L4), the non-dominant one-third radius and the hip were measured using dual-energy $\mathrm{X}$-ray absorptiometry (DXA; Hologic QDR-4500A, Hologic, Inc., Waltham, MA). The soft tissue body composition (fat mass [FM, kg], percentage of body fat mass [\% FM] and lean mass [LM, $\mathrm{kg}]$ ) were derived from the whole-body scan. The same operator, after following standard quality control procedures, performed all scanning and analysis to ensure consistency. Quality control for DXA was checked daily by scanning a lumbar spine phantom consisting of calcium hydroxyapatite embedded in a cube of thermoplastic resin (DPA/QDR-1; Hologic X-calibre anthropometrical spine phantom). The coefficients of variation (CV) given by the manufacturer were $0.8 \%$ for spine and radius, $1.1 \%$ at the total proximal femur, and $<1 \%$ for LM and FM.

aBMD values are expressed as absolute values $\left(\mathrm{g} / \mathrm{cm}^{2}\right)$ or as Z-scores, which reflect the comparison between the absolute value of each subject and the age-based norm using the Hologic white female and male database. The Z-score is the number of standard deviations a patient's aBMD differs from the average aBMD corresponding to their age and sex in the whole population.

\subsection{Osteopenia and osteoporosis definition}

Osteopenia and osteoporosis were defined according to WHO criteria [12]: osteopenia by the lowest T-score at the spine or hip between -1 and -2.5 , and osteoporosis by a T-score at the spine or hip $\leq-2.5$. Normal bone density was defined by a T-score at the spine and total hip $\geq-1$.

\section{Statistical analysis}

The characteristics of the patients are described with proportions for categorical variables and with means \pm standard deviations (SD) for quantitative variables. The continuous variable distributions were tested by the Shapiro-Wilk statistical test.

We first estimated Z-scores of aBMD adjusted for age according to bone site and gender, using a linear mixed model to account for correlations between the measurements of different bone sites. This model included a subject-specific random intercept; the fixed effects were age, aBMD site, gender and the two-way and three-way interaction terms between these three variables. We then customized statistical tests (using "estimate" function in PROC MIXED) in order to compare (1) the estimated value of Z-score (and change of Z-score with age) to 0 for each bone site for men and women, (2) the estimated value of $\mathrm{Z}$-score (and change of Z-score with age) between men and women for each bone site, (3) the estimated value of Z-score (and change in $Z$-score with age) between each bone site for men and women. The effect of obesity grade was analysed separately for men and women using the same type of linear mixed model and statistical test. These models included a subject-specific random intercept; fixed effects were age, aBMD sites, grade of obesity and the two-way and three-way interaction terms between these variables. As Z-scores were linked with age in our obese population, we had to set an age of interest to compute these estimates and comparisons. We set age to 49.6 years, as this was the mean age of the cohort. Finally, we analysed the effects of fat mass and lean mass, and their interactions with gender and aBMD sites, first separately then jointly, in order to account for the potential confounding effect of one another. We used linear mixed models with subject-specific random intercept adjusted for age, aBMD sites, gender, the two-way and three-way interaction terms between these variables, height and interaction between height and aBMD sites.

The relationship between aBMD and age has also been analysed graphically for each bone site in men and women (and according to the grade of obesity) using thin plate regression spline models. The smoothing parameters have been chosen by minimizing the generalized cross validation function. The results are expressed graphically with their 95\% Bayesian confidence interval.

In order to control for the family wise error rate, we used Tukey's (when possible) or Hochberg's multiple comparison procedures. Statistical analyses were performed at the conventional two-tailed $\alpha$ level of 0.05 using SAS version 9.2 (SAS Institute, Cary, NC).

\section{Results}

\subsection{Patients' characteristics}

A total of 504 obese patients [ 363 women (72\%) and 141 men (28\%)] with age ranging from 18.1 to 81.9 years (mean $49.6 \pm 14.6$ ) participated in this study. Therefore, this age range included the period from youth to elderly. Women had a mean BMI of $38.8 \pm 6.0 \mathrm{~kg} / \mathrm{m}^{2}$, with $40.4 \%$ having class I obesity, $38.3 \%$ class II, and $34.4 \%$ class III. Men had a mean BMI of $37.9 \pm 6.0 \mathrm{~kg} / \mathrm{m}^{2}$, with $40.4 \%$ having class I 
obesity, $31.9 \%$ class II, and $27.7 \%$ class III. Baseline characteristics of the patients according to the gender are summarized in Table 1.

4.2. Variations of aBMD and Z-score according to the bone site and the gender

Tables 1 and 2 present the values of aBMD $\left(\mathrm{g} / \mathrm{cm}^{2}\right)$ and Z-score (SD) at various bone sites according to the gender. All the Z-score means, except at L1-L4 site for men, were significantly different from 0 (i.e. aBMD significantly above the age- and gender-related average value in the whole population) for all bone sites: whole-body ( 0.79 SD, $p<0.01$ for women; 0.32 SD, $p<0.01$ for men), total hip (1.09 SD, $p<0.01 ; 1.06$ SD, $p<0.001$ ), one-third radius ( 0.32 SD, $p<0.01 ; 0.50$ SD, $p<0.01)$ and L1-L4 ( $0.86 \mathrm{SD}, \mathrm{p}<0.01$ for women only). Furthermore, the analysis by bone site in men demonstrated that means of Z-score were higher at the hip than at the L1-L4, one-third radius and whole-body. For women, $Z$-scores were higher at the one-third radius than at the other three bone sites and Z-score was higher at the hip than L1-L4 and wholebody (Table 2). When comparisons were performed according to gender, Z-scores were significantly higher in women than in men, for all bone sites, hip excepted.

\subsection{Variations of $a B M D$ and Z-score according to the bone site and ageing}

For women, aBMD decreased significantly with age at all bone sites, while in men we observed no variation with age, except at the L1-L4 level (data not shown). However, Z-score increased significantly with age at all bone sites for women, with these differences more marked at L1-L4 and one-third radius levels (Table 2). For a given age, no significant effect of menopause was demonstrated on Z-score variation regardless of the bone site (data not shown). For men, Z-score also

Table 1

Characteristics of study population.

\begin{tabular}{lll}
\hline & Females & Males \\
\hline Number of subjects & 363 & 141 \\
Age (years) & $48.3 \pm 14.7[18.1-80.1]$ & $52.9 \pm 13.4[19.5-81.9]$ \\
Anthropometric data & & \\
Weight (kg) & $101.9 \pm 17.1[65-163]$ & $114.9 \pm 19.1[83.3-185.7]$ \\
Height (cm) & $162.1 \pm 6.9[134-182]$ & $174.2 \pm 7.5[149-190]$ \\
BMI (kg.m ${ }^{-2}$ ) & $38.8 \pm 6.0[30-61.8]$ & $37.9 \pm 6.0[30.3-66.2]$ \\
Waist circumference (cm) & $112.4 \pm 13.2[79-161]$ & $122.2 \pm 12.7[93-155]$ \\
Hip circumference (cm) & $124.9 \pm 12.7[103-166]$ & $118.1 \pm 12.7[75-162]$ \\
WB FM (\%) & $45.0 \pm 4.7[27.8-63.2]$ & $35.4 \pm 6.3[21.2-53.44]$ \\
WB FM (kg) & $46.8 \pm 11.0[24.5-80.8]$ & $41.6 \pm 12.6[19.4-96.5]$ \\
WB FFST (kg) & $54.8 \pm 7.9[34.7-72.5]$ & $72.5 \pm 9.1[44.8-93.9]$ \\
& & \\
Clinical data & & \\
Menopausal status (n, \%) & $191(52.6 \%) / 172(47.8 \%)$ & - \\
$\quad$ (pre -/post-menopausal) & & \\
Smoking (n, \%) & $46(14.7 \%) / 49(15.7 \%) / 217$ & $20(15.6 \%) / 52(40.6 \%) / 56$ \\
$\quad$ current, former, never) & $(69.6 \%)$ & $(43.7 \%)$ \\
Diabetes mellitus (n, \%) & $90(24.8 \%)$ & $62(44.0 \%)$ \\
Blood parameters & & \\
Calcium (mmol/l) & $2.36 \pm 0.17[0.60-3.2]$ & $2.36 \pm 0.16[0.98-2.63]$ \\
Phosphorus(mmol/l) & $1.12 \pm 0.34[0.51-5.1]$ & $1.02 \pm 0.19[0.61-1.57]$ \\
$\quad$ (mmol/l) & & \\
& & \\
Areal bone mineral density & & \\
WB (g.cm ${ }^{-2}$ ) & $1.11 \pm 0.10[0.87-1.50]$ & $1.19 \pm 0.1[0.94-1.55]$ \\
Z-score WB (SD) & $0.78 \pm 1.07[-2.2-5.8]$ & $0.37 \pm 1.04[-2.4-4]$ \\
L1-L4 (g.cm ${ }^{-2}$ ) & $1.04 \pm 0.14[0.62-1.53]$ & $1.07 \pm 0.16[0.75-1.68]$ \\
Z-score L1-L4 (SD) & $0.77 \pm 1.26[-2.8-5.7]$ & $0.27 \pm 1.54[-2.9-6]$ \\
Hip (g.cm ${ }^{-2}$ ) & $1.03 \pm 0.13[0.56-1.40]$ & $1.12 \pm 0.14[0.72-1.44]$ \\
Z-score hip (SD) & $1.08 \pm 1.06[-2.1-4.4]$ & $1.12 \pm 1.1[-1.7-3.7]$ \\
1/3 Radius (g.cm ${ }^{-2}$ ) & $0.72 \pm 0.07[0.37-0.92]$ & $0.80 \pm 0.09[0.46-1.00]$ \\
Z-score 1/3 radius (SD) & $1.68 \pm 1.25[-1.3-6.0]$ & $0.63 \pm 1.49[-3.4-7.0]$ \\
\hline
\end{tabular}

Legend: Data are represented by mean \pm standard deviation [minimum-maximum]. WB: whole body; FM, fat mass; FFST: fat free soft tissue; L1-L4: lumbar spine; FN: femoral neck; $1 / 3$ radius: one-third radius; $Z$-score: $Z$-score is defined as a difference (SD) with a gender- and age-matched population; SD: standard deviation.
Table 2

Z-score means of areal bone mineral density adjusted for age, and mean changes in $Z$-scores with age: comparison to reference values $(Z$-score $=0$ ) according to gender and bone sites.

\begin{tabular}{|c|c|c|c|c|c|}
\hline & Females $^{*}$ & p-value ${ }^{* *}$ & Males* & p-value ${ }^{* *}$ & $\begin{array}{l}\text { Females vs } \\
\text { males } \\
\text { p-value }\end{array}$ \\
\hline \multicolumn{6}{|c|}{ Z-score means (SEM) for a 49.6 years old subject. } \\
\hline Whole body & $0.79(0.06)^{a}$ & $<0.01$ & $0.32(0.10)^{\mathrm{a}}$ & $<0.01$ & $<0.01$ \\
\hline L1-L4 & $0.86(0.06)^{\mathrm{a}}$ & $<0.01$ & $0.15(0.10)^{\mathrm{a}}$ & 0.13 & $<0.01$ \\
\hline Hip & $1.09(0.06)^{b}$ & $<0.01$ & $1.06(0.10)^{b}$ & $<0.01$ & 1.00 \\
\hline 1/3 Radius & $1.70(0.06)^{c}$ & $<0.01$ & $0.45(0.10)^{\mathrm{a}}$ & 0.012 & $<0.01$ \\
\hline \multicolumn{6}{|c|}{ Mean change in Z-scores (SEM) for an increasing of 10 years of age } \\
\hline Whole body & $0.11(0.04)^{a}$ & $<0.01$ & $0.06(0.07)^{\mathrm{a}}$ & 0.37 & 0.58 \\
\hline L1-L4 & $0.28(0.04)^{b}$ & $<0.01$ & $0.39(0.07)^{b}$ & $<0.01$ & 0.16 \\
\hline Hip & $0.17(0.04)^{\mathrm{a}}$ & $<0.01$ & $0.17(0.07)^{a}$ & 0.01 & 0.91 \\
\hline 1/3 Radius & $0.32(0.04)^{\mathrm{b}}$ & $<0.01$ & $0.50(0.07)^{\mathrm{b}}$ & $<0.01$ & 0.04 \\
\hline
\end{tabular}

Legend: ${ }^{*} Z$-score means, or mean changes in Z-score, are not significantly different $(p>0.05)$ according to bone site for a given gender when they share the same letter. ${ }^{* *}$ p-value $<0.05$ indicates that Z-score means, or mean changes in Z-score, are significantly different from 0 .

L1-L4: lumbar spine, 1/3 radius: one-third radius.

As Z-scores were linked to age in our obese population, we had to set an age in our models in order to give punctual estimations of Z-scores and compare these estimates to 0 and between groups. We chose to set age to 49.6 years, as it was the mean age of the cohort.

increased significantly with age at L1-L4, hip and one-third radius levels. Furthermore, excepted at one-third radius, Z-score increased similarly with age in men and in women. The variations of aBMD and Z-score with age from 18.1 to 81.9 years, according to the gender are graphically represented in Fig. 1. See Fig. 2

\subsection{Prevalence of osteopenia and osteoporosis in obese patients}

Over 50 years old, $73.3 \%$ of women had normal aBMD, $18.5 \%$ were osteopenic, and $8.3 \%$ were osteoporotic, while for men, the repartition was $70.1 \%, 26.0 \%$ and $3.9 \%$, respectively.

\subsection{Variation of aBMD and Z-score according to obesity severity}

In order to analyse the effect of obesity severity on aBMD, the patients were subdivided according to their BMI class (1,2 or 3 ) (Table 3 ). For women, regardless of BMI or bone site, Z-scores were significantly higher than 0 , the increase of whole-body Z-score being more marked than at L1-L4 and hip bone sites for grade 3 obesity patients compared to grade 1 and 2 obese patients. For men, Z-score was significantly higher than 0 at the hip, without any effect of obesity severity. Although a gain of Z-score with age was demonstrated at various bone sites in men and women, no difference according to BMI class was identified in this study.

\subsection{Relationship between Z-score and body composition}

Relationship between Z-score and body composition (fat mass and lean mass) according to the bone site is summarized in Table 4. In women, an increase of fat mass or lean mass was positively correlated with an increase of Z-score at all bone sites. Moreover, influence of the effect of lean mass on Z-score appeared site-dependent. In men, only an effect of lean mass on hip and whole-body's Z-score was observed, without any bone site difference. When fat mass and lean mass were concomitantly entered into the models, only lean mass was correlated to Z-score in men at hip and whole-body levels and in women at all sites with a site-dependent effect. No gender effect was in relation to the effect of fat mass or lean mass on the Z-score.

\section{Discussion}

In this study, we modelled for the first time, the effect of obesity on aBMD according to gender, age, bone site and obesity severity 


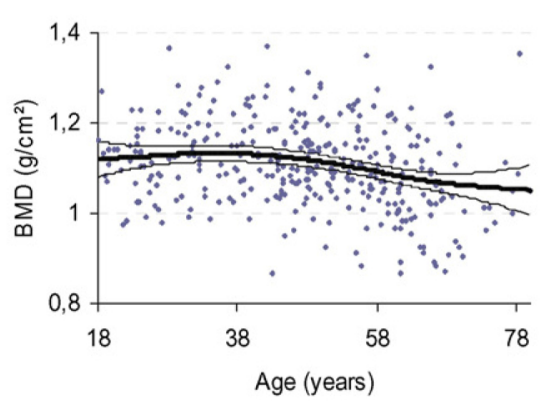

Whole body

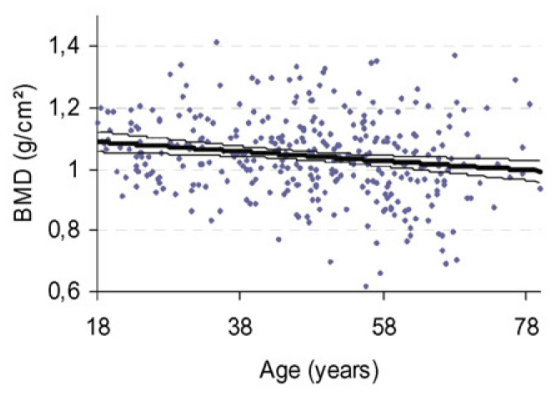

L1-L4

Hip

Radius
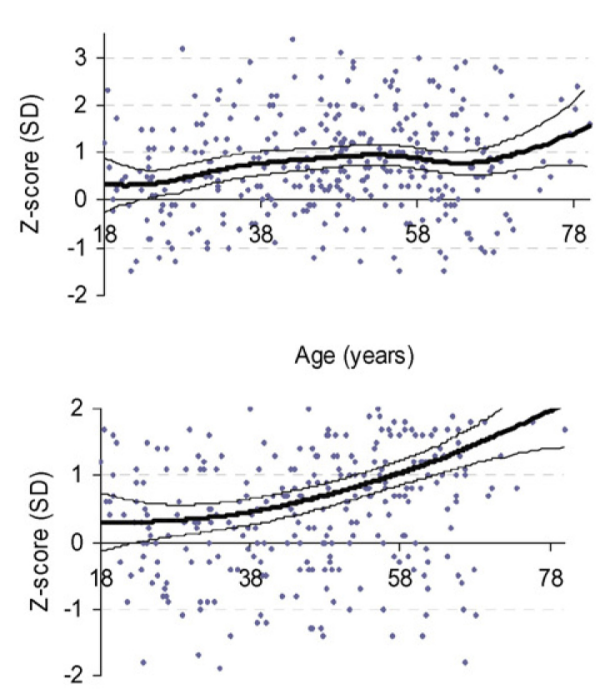

Age (years)

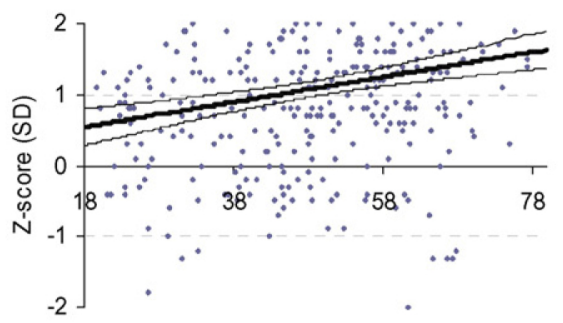

Age (years)

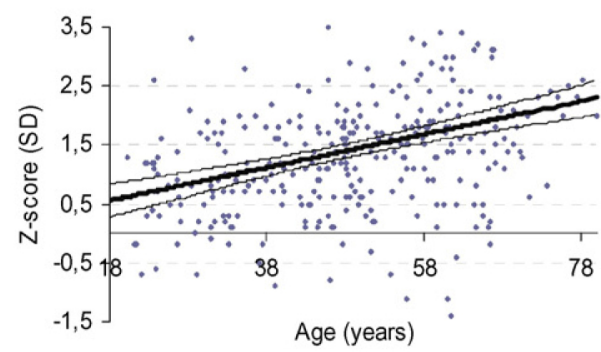

Fig. 1. Modelling of areal bone mineral density (aBMD) and Z-score variations at various bone sites in women obese patients. The dashed curves represent the $95 \%$ confidence interval.

throughout adult life, using a large sample of well-characterized obese patients. Our results clearly show that obese patients display higher aBMD than normal-weight subjects, the effect of obesity being further accentuated with ageing. Furthermore, the magnitude of this effect depends on the gender, obesity severity and bone site.

Our cross-sectional analysis demonstrated that patients suffering from obesity present elevated aBMD. Furthermore, Z-scores indicated that the improvement of bone mass was observable not only for the whole skeleton, but also at central (lumbar spine and hip) and appendicular skeletal sites (one-third radius). aBMD in obese patients was higher from $+5.6 \%$ at whole body to $+15.2 \%$ at the hip level, strongly confirming previous works $[3,6,13]$. This may be attributable to a positive balance between bone formation and bone resorption in obese patients, as previously evaluated by bone turnover markers [6]. Moreover, the analysis in subgroup according to gender provided new data, suggesting that bone tissue is more sensitive to obesity-related effects in women than in men. This was demonstrated by systematic higher Z-scores at whole-body, L1-L4 and one-third radius levels in women compared to men. Conversely, no difference between groups was observed at the hip. Previous work did not find any interaction between obesity and gender on aBMD, probably due to the limited number of participants, but demonstrated a gender interaction with some bone parameters (i.e., cortical tissue mineral density or cortical thickness) determined by HR-pQCT, which support some of the conclusions of our study [6].

Data from the literature suggest that high aBMD values in obese patients are due to an increase in body mass that accentuates mechanical loading on the skeleton [3]. Indeed, bone is an adaptive tissue that presents the capacity to modify its mass and its microarchitecture in response to a mechanical stimulus [14]. This hypothesis may partially or totally explain the similar increased in aBMD values observed in both men and women at the hip, a weight-bearing bone site. The subdivision of our cohort according to WHO classification for BMI reinforced our hypothesis, as women with BMI values above $40 \mathrm{~kg} / \mathrm{m}^{2}$ (grade 3 obesity) present the higher aBMD values at the hip. These results suggest that obesity severity is the main determinant of bone mass gain at the weight-bearing bone sites. Our observations are therefore in accordance with extensive data showing positive correlation between weight or BMI and aBMD [15-17]. These correlations were reported both in men and women, across the entire adult age range, and throughout the skeleton [15-17]. 

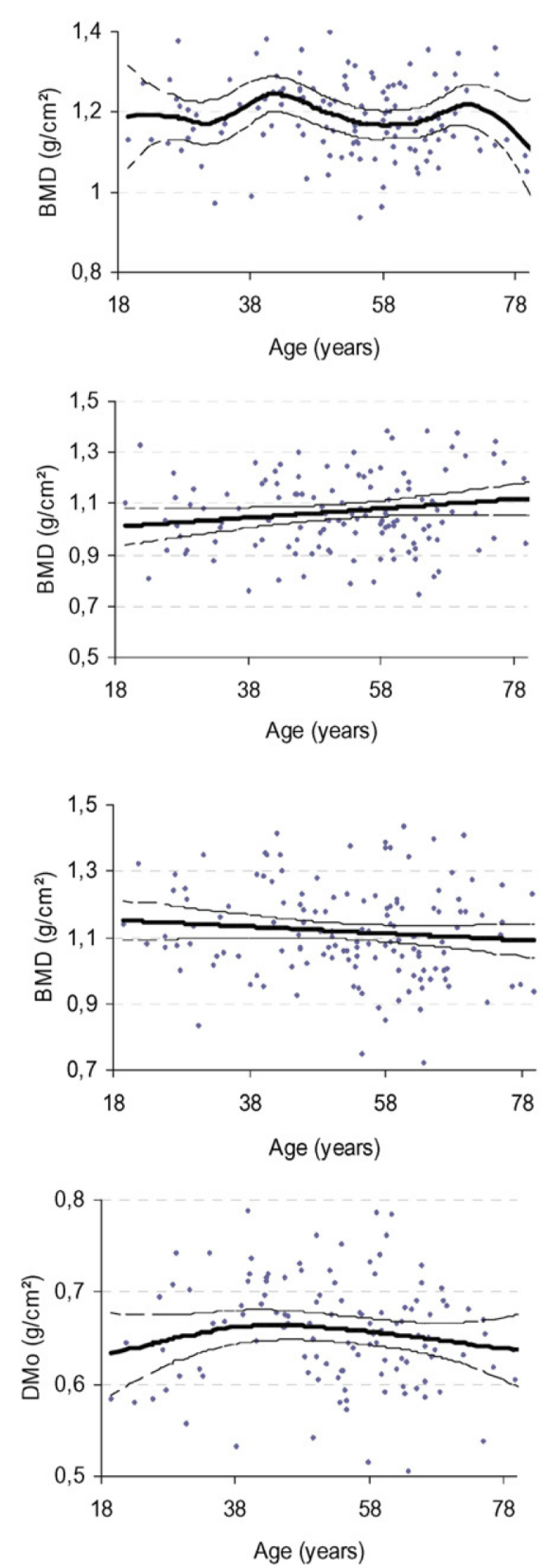

\section{Whole body}

L1-L4

Hip

Radius
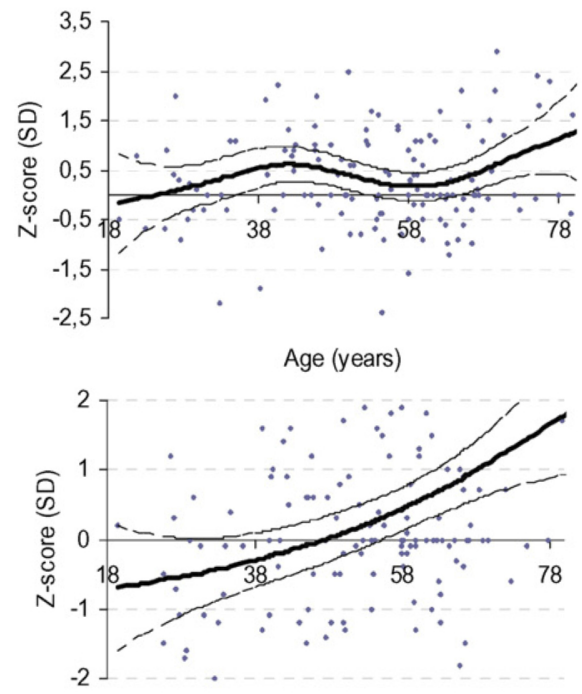

Age (years)

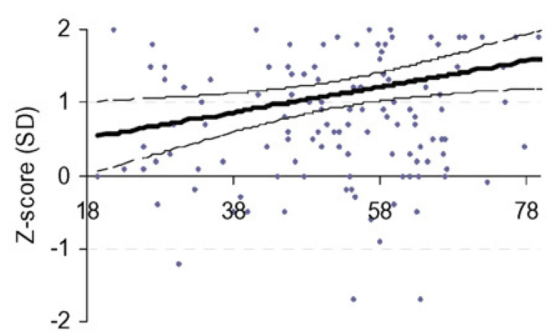

Age (years)

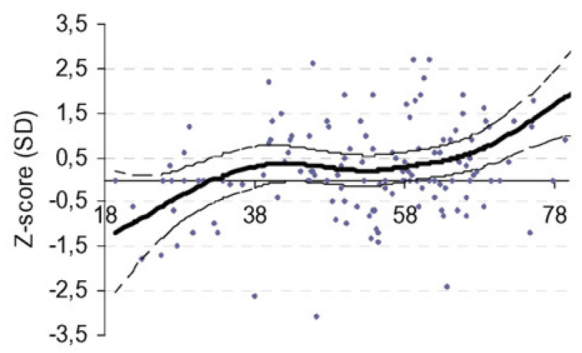

Age (years)

Fig. 2. Modelling of areal bone mineral density (aBMD) and Z-score variations at various bone sites in men obese patients. The dashed curves represent the $95 \%$ confidence interval.

More surprisingly, we confirm a higher $a B M D$ values at the onethird radius [18,19], a less mechanical solicited bone site, particularly in women. Therefore, these specifics bone mass $[18,19]$ and microarchitecture adaptations, as previously demonstrated [5,6], cannot only be induced by gravitational forces associated with increased body weight. Indeed, these results suggest the possibility that systemic biologically active molecules secreted by adipose tissue may interact with bone metabolism. Increased leptin production $[20,21]$, as well as oestrogens synthesis $[9,16]$ by adipocytes may have positive actions on bone mass and thus limit fracture risk [22]. Higher bone mass density in obese patients suggests that the effects of favourable factors overpass those of detrimental ones such as reduction of testosterone, vitamin $D$ levels and growth hormone secretion as well as the increase of parathyroid hormone (PTH) and proinflammatory cytokine levels frequently described in this population [4,9,17,23-25]. Moreover, as suggested by both higher Z-score in women compared to men and systematic highest Z-score with BMI in women, one-third radius excepted, it is probable that the imbalance between beneficial and detrimental factors is accentuated with age at trabecular bones (i.e., lumbar spine) in women, with a BMI-dependent effect. Among the hypotheses that may explain this gender difference, it is probable that the greater oestrogen synthesis in adipose tissue of obese patients would have more impact on postmenopausal women 'aBMD than on eugonadal men' aBMD.

Among our obese patients, some of them presented concomitantly type-2 diabetes mellitus, a disease known to influence aBMD and bone geometry [26,27]. Then, despite a difference in diabetes prevalence between men (44\%) and women (24.8\%) was observed, the results of sensitivity analyses led to similar conclusions regarding gender effect, with or without adjustment for diabetes condition (data not shown). Briefly, the inclusion of a "diabetes effect" in our models did not change our conclusions regarding the impact of obesity on aBMD.

BMI is an index widely used for diagnosis of obesity and estimation of its severity. However, even if it is easy to calculate, it does not reflect 
Table 3

Z-score means and mean changes in Z-scores with age: comparison with reference values $(\mathrm{Z}$-score $=0)$ according to bone site and BMI class.

\begin{tabular}{|c|c|c|c|c|c|}
\hline & & Females ${ }^{*}$ & p-value ${ }^{* *}$ & Males ${ }^{*}$ & p-value ** \\
\hline \multicolumn{6}{|c|}{ Z-scores means (SEM) for a 49.6 years old subject } \\
\hline \multirow[t]{3}{*}{ Whole body } & $30-35$ & $0.53(0.11)^{\mathrm{a}}$ & $<0.01$ & $0.22(0.19)$ & 0.25 \\
\hline & $35-40$ & $0.64(0.09)^{\mathrm{a}}$ & $<0.01$ & $0.37(0.18)$ & 0.05 \\
\hline & $>40$ & $1.15(0.10)^{\mathrm{b}}$ & $<0.01$ & $0.30(0.20)$ & 0.14 \\
\hline \multirow[t]{3}{*}{ L1-L4 } & $30-35$ & $0.71(0.11)^{\mathrm{a}}$ & $<0.01$ & $0.12(0.19)$ & 0.52 \\
\hline & $35-40$ & $0.74(0.09)^{\mathrm{a}}$ & $<0.01$ & $0.18(0.19)$ & 0.34 \\
\hline & $>40$ & $1.09(0.10)^{b}$ & $<0.01$ & $0.26(0.21)$ & 0.21 \\
\hline \multirow[t]{3}{*}{ Hip } & $30-35$ & $0.80(0.11)^{\mathrm{a}}$ & $<0.01$ & $0.94(0.18)$ & $<.01$ \\
\hline & $35-40$ & $0.90(0.09)^{\mathrm{a}}$ & $<0.01$ & $1.11(0.18)$ & $<.01$ \\
\hline & $>40$ & $1.52(0.09)^{\mathrm{b}}$ & $<0.01$ & $1.16(0.19)$ & $<.01$ \\
\hline \multirow[t]{3}{*}{ 1/3 Radius } & $30-35$ & $1.55(0.11)$ & $<0.01$ & $0.50(0.19)$ & 0.01 \\
\hline & $35-40$ & $1.73(0.09)$ & $<0.01$ & $0.47(0.18)$ & 0.01 \\
\hline & $>40$ & $1.77(0.10)$ & $<0.01$ & $0.29(0.20)$ & 0.18 \\
\hline \multicolumn{6}{|c|}{ Mean change in Z-scores (SEM) for an increasing of 10 years of age } \\
\hline \multirow[t]{3}{*}{ Whole body } & $30-35$ & $0.01(0.08)$ & 0.92 & $0.18(0.13)$ & 0.16 \\
\hline & $35-40$ & $0.13(0.06)$ & 0.04 & $0.01(0.15)$ & 0.95 \\
\hline & $>40$ & $0.10(0.07)$ & 0.12 & $-0.02(0.13)$ & 0.89 \\
\hline \multirow[t]{3}{*}{ L1-L4 } & $30-35$ & $0.15(0.08)$ & 0.05 & $0.33(0.13)$ & 0.01 \\
\hline & $35-40$ & $0.27(0.07)$ & $<0.001$ & $0.39(0.15)$ & $<.01$ \\
\hline & $>40$ & $0.35(0.07)$ & $<0.001$ & $0.50(0.14)$ & $<.01$ \\
\hline \multirow[t]{3}{*}{ Hip } & $30-35$ & $0.09(0.08)$ & 0.24 & $0.11(0.13)$ & 0.37 \\
\hline & $35-40$ & $0.22(0.07)$ & 0.001 & $0.32(0.14)$ & 0.02 \\
\hline & $>40$ & $0.10(0.07)$ & 0.15 & $0.15(0.13)$ & 0.26 \\
\hline \multirow[t]{3}{*}{ 1/3 Radius } & $30-35$ & $0.28(0.08)$ & $<0.001$ & $0.56(0.13)$ & $<.01$ \\
\hline & $35-40$ & $0.35(0.07)$ & $<0.001$ & $0.48(0.14)$ & $<.01$ \\
\hline & $>40$ & $0.29(0.07)$ & $<0.001$ & $0.39(0.16)$ & 0.01 \\
\hline
\end{tabular}

Legend: ${ }^{*}$ Z-scores means, or mean changes in Z-score, are not significantly different $(p>0.05)$ according to obesity grade for a given gender and a given bone site when they share the same letter.

${ }^{* *}$ p-value $<0.05$ indicates that $Z$-score means, or mean change in Z-score, are significantly different from 0 .

L1-L4: lumbar spine; $1 / 3$ radius: one-third radius.

As Z-scores were linked to age in our obese population, we had to set an age in our models in order to give punctual estimations of Z-scores and compare these estimates to 0 and between groups. We chose to set age to 49.6 years, as it was the mean age of the cohort.

body composition. In our study, fat and lean mass values were precisely evaluated by DXA. We found that Z-score correlates better with dynamic load resulting from muscle mass rather than static load from fat mass. Moreover, analysis of models evaluating the independent effects of fat mass and lean mass demonstrated that only lean mass was independently linked to Z-score, without any gender effect. In agreement with our findings, lean mass appeared to be positively associated with aBMD or parameters of microarchitecture, while fat mass appeared to be negatively or not correlated at all to bone mass $[6,17,28,29]$. All of these results suggest that lean mass, rather than fat mass, has protective effect on bone mass in obese patients. Moreover, Zhao et al., [28] demonstrated that the effects of lean mass are not entirely attributable to mechanical loading of body weight, but are also due to the direct action of muscle contractions on the skeleton. These findings may have a considerable clinical implication as maintenance of lean mass during weight loss in obese patients may contribute to preserve bone health.

Although numerous studies have previously evaluated the effect of obesity on aBMD with cross-sectional approaches $[3,6,13,17]$, the specific and original design of our work provides new relevant information. Our large cohort of patients gave us the opportunity to analyse the effect of obesity on aBMD from peak bone mass to elderly periods, which, to our knowledge, has never been described before. Our results clearly show that obese patients, as early as 18 years old, present a significant difference in aBMD compared to reference values in most of the bone sites analysed, this effect being gender-dependent. These results indicate that the higher bone mass in obese patients is precocious and probably starts during adolescence, although divergent results have been reported [30,31]. Moreover, we found that Z-score increases significantly with age in obese patients, thus indicating that bone loss is reduced in
Table 4

Relationship between Z-score and body composition: fat mass and lean mass.

\begin{tabular}{|c|c|c|c|c|c|}
\hline & Females ${ }^{*}$ & $\mathrm{p}$-value ${ }^{* *}$ & Males* & p-value ${ }^{* *}$ & $\begin{array}{l}\text { Female } \\
\text { vs male } \\
\text { p-value }\end{array}$ \\
\hline \multicolumn{6}{|c|}{ 1st model: Mean change in Z-score (SEM) for an increase of $10 \mathrm{~kg}$ of fat mass ${ }^{\dagger}$} \\
\hline Whole body & $0.17(0.06)$ & $<0.01$ & $0.03(0.08)$ & 0.68 & 0.16 \\
\hline L1-L4 & $0.11(0.06)$ & 0.06 & $0.06(0.08)$ & 0.47 & 0.62 \\
\hline Hip & $0.19(0.06)$ & $<0.01$ & $0.06(0.08)$ & 0.46 & 0.19 \\
\hline 1/3 Radius & $0.07(0.06)$ & 0.21 & $-0.08(0.09)$ & 0.32 & 0.13 \\
\hline \multicolumn{6}{|c|}{ 2nd model: Mean change in Z-score (SEM) for an increase of $10 \mathrm{~kg}$ of lean mass ${ }^{\dagger}$} \\
\hline Whole body & $0.47(0.08)^{\mathrm{a}}$ & $<0.01$ & $0.38(0.12)^{a}$ & $<0.01$ & 0.42 \\
\hline L1-L4 & $0.24(0.08)^{b}$ & $<0.01$ & $0.20(0.12)^{a, b}$ & 0.11 & 0.80 \\
\hline Hip & $0.41(0.08)^{a, b}$ & $<0.01$ & $0.30(0.12)^{\mathrm{a}, \mathrm{b}}$ & 0.01 & 0.49 \\
\hline 1/3 Radius & $0.19(0.09)^{b}$ & 0.03 & $-0.01(0.12)^{b}$ & 0.91 & 0.14 \\
\hline \multicolumn{6}{|c|}{ 3rd model: Mean change in Z-score (SEM) for an increase of $10 \mathrm{~kg}$ of fat mass ${ }^{\dagger \dagger}$} \\
\hline Whole body & $0.05(0.06)$ & 0.43 & $-0.07(0.08)$ & 0.42 & 0.26 \\
\hline L1-L4 & $0.05(0.06)$ & 0.41 & $0.04(0.08)$ & 0.63 & 0.91 \\
\hline Hip & $0.09(0.06)$ & 0.15 & $-0.00(0.08)$ & 0.97 & 0.38 \\
\hline 1/3 Radius & $0.01(0.06)$ & 0.85 & $-0.12(0.09)$ & 0.16 & 0.21 \\
\hline \multicolumn{6}{|c|}{ 3rd model: Mean change in Z-score (SEM) for an increase of $10 \mathrm{~kg}$ of lean mass ${ }^{\dagger \dagger}$} \\
\hline Whole body & $0.44(0.09)$ & $<0.01$ & $0.41(0.12)^{a}$ & $<0.01$ & 0.82 \\
\hline L1-L4 & $0.20(0.09)$ & 0.04 & $0.18(0.13)^{a, b}$ & 0.16 & 0.92 \\
\hline Hip & $0.35(0.09)$ & $<0.01$ & $0.30(0.12)^{a, b}$ & 0.01 & 0.77 \\
\hline 1/3 Radius & $0.19(0.10)$ & 0.07 & $0.03(0.12)^{\mathrm{b}}$ & 0.79 & 0.29 \\
\hline
\end{tabular}

Legend: SEM: standard error of mean. *The changes in Z-scores are not significantly different $(p>0.05$ ) according to bone location for a given gender when they share the same letter or when no letter is displayed. Models are adjusted for the effect of age and height for each bone site.

L1-L4: lumbar spine; $1 / 3$ radius: one-third radius.

${ }^{* *} \mathrm{p}$-value $<0.05$ indicates that the change of Z-scores for a $10-\mathrm{kg}$ fat mass (or lean mass) increase is significantly different from 0 .

${ }^{\dagger} 1$ st and 2 nd models: lean mass and fat mass are analysed in different model adjusted for age and height.

T3rd model: lean mass and fat mass are analysed concomitantly, in a model adjusted for age and height, in order to account for the potential confounding effect of one another.

this population compared to normal-weight subjects. This may be due to a lack of increase in bone turnover, typically observed with ageing [6]. Our results are in agreement with those from Evans et al., who, by comparing obese and normal-weight adults, found greater differences in aBMD in older adults than in younger adults [6]. Consequently, the association of both improvement of peak bone mass and reduction of bone loss may protect obese patients from osteopenia and osteoporosis. In this study, we confirm the low incidence of osteopenia or osteoporosis in obese patients over 50 years old [13], with $26.0 \%$ and $3.9 \%$ in men, and $18 . \%$ and $8.2 \%$ in women, respectively. This prevalence appeared to be reduced compared to that reported from the OFELY (Os des Femmes de Lyon) cohort, including French postmenopausal women with $48 \%$ of them being osteopenic and $21 \%$ osteoporotic [32].

The higher $a B M D$ values in obese patients identified in our crosssectional and modelling approaches, associated with a low prevalence of osteoporosis suggests an improvement of bone strength and a low risk of fragility fracture. However, it was demonstrated a nonlinear pattern in the relationship between fracture risk and BMI [33,34], and although there was a pronounced increase in hip fracture risk from normal to low BMI, there was a much more modest [33] or even no [35] reduction in the risk of fracture in overweight and obese people compared to people with normal BMI. Moreover, site-specific effects of obesity on fracture risk have been reported, characterized by a lower risk of hip fracture and higher risk of proximal humerus, ankle, lower and upper leg fractures in obese patients compared to non-obese individuals $[35,36]$. The mechanisms involved in site-related differences in fracture risk in obese patients are not precisely known. Nevertheless, the increase of aBMD at specific bone sites is probably insufficient to resist to increased forces imposed to the skeleton by raised body mass during fall $[13,37]$, the greater risk of fall [7] or the different patterns of falls [36]. Of note, in some anatomic sites, the higher values of soft tissue padding may explain the protection against hip fracture in women [38]. 
These observations may explain why fracture risk is increased in obese patients with low or normal aBMD compared to those with the highest aBMD [13,39]. Furthermore, the difference of bone gain between obese men and women may account for the difference of fracture risk according to gender [33]. Finally, our findings highlight a lack of accuracy in definitions of both osteopenia and osteoporosis used in the general population, as a new specific classification should be addressed, taking into account the BMI to be fully applicable to obese people.

The main limitations of this study are related to the lack of a normal weight control group. Therefore, NHANES reference values were used, which may not be totally representative to all populations. Moreover, the cross-sectional design implicated that the causality of our findings cannot be demonstrated. However, we believe that such limitations are partially compensated by the large sample of patients, stratified by gender and within a large age range, as well as our exhaustive characterization, providing a faithful representation of the aBMD variation in obese patients with age. The accurate measurement of aBMD in obese patients with DXA is difficult, due to large amounts of adipose tissue that can falsely increase apparent bone density, particularly in lumbar spine and, to a lesser extent, in the femur $[40,41]$. However, the same demonstration of high aBMD at one-third radius, a bone site where measurement is less affected by adipose tissue, strongly suggests that the difference observed between obese and normal-weight subjects is mainly attributed to a physiological effect rather than an error of measurement. This assumption is reinforced by the comparable magnitude of the difference in bone density observed between obese and normalweight individuals using DXA or high resolution peripheral quantitative computed tomography (HR-pQCT) [6]. Unfortunately, fractures were not recorded; therefore we could not evaluate the relationship between aBMD or Z-score values and fracture risk.

In conclusion, although our study highlights the complexity of obesity effect on bone mass, we showed that obese patients present a higher $a B M D$ values at weight-bearing and non-weight bearing bone sites, with a specific response depending on bone location. The improvement of aBMD is already present in young subjects and is accentuated with ageing, suggesting that the beneficial effect of obesity on bone mass is related to age. However, bone tissue in women is particularly sensitive to the increase of weight or BMI indicating a gender-specific bone response to obesity. Our modelling highlights a very large dispersion of absolute aBMD or Z-score values suggesting that, if it seems that higher BMI provides the benefit of greater aBMD in most of obese patients, this effect is not guaranteed. Consequently, it is necessary to identify other factors that could play a role in bone tissue adaptation to obesity.

\section{Acknowledgements}

The authors would like to express their thanks to the patients for their participation.

\section{References}

[1] Y.C. Wang, K. McPherson, T. Marsh, S.L. Gortmaker, M. Brown, Health and economic burden of the projected obesity trends in the USA and the UK, Lancet 378 (2011) $815-825$.

[2] T. Andreyeva, P.C. Michaud, A. van Soest, Obesity and health in Europeans aged 50 years and older, Public Health 121 (2007) 497-509.

[3] S. Andersen, K.D. Frederiksen, S. Hansen, K. Brixen, J. Gram, R.K. Stoving, Bone structure and estimated bone strength in obese patients evaluated by highresolution peripheral quantitative computed tomography, Calcif. Tissue Int. 95 (2014) 19-28.

[4] M.A. Bredella, M. Torriani, R.H. Ghomi, B.J. Thomas, D.J. Brick, A.V. Gerweck, L.M. Harrington, A. Breggia, C.J. Rosen, K.K. Miller, Determinants of bone mineral density in obese premenopausal women, Bone 48 (2011) 748-754.

[5] E. Sornay-Rendu, S. Boutroy, N. Vilayphiou, B. Claustrat, R.D. Chapurlat, In obese postmenopausal women, bone microarchitecture and strength are not commensurate to greater body weight: the Os des Femmes de Lyon (OFELY) study, J. Bone Miner. Res. 28 (2013) 1679-1687.

[6] A.L. Evans, M.A. Paggiosi, R. Eastell, J.S. Walsh, Bone density, microstructure and strength in obese and normal weight men and women in younger and older adulthood, J. Bone Miner. Res. 30 (2015) 920-928.
[7] T.J. Beck, M.A. Petit, G. Wu, M.S. LeBoff, J.A. Cauley, Z. Chen, Does obesity really make the femur stronger? BMD, geometry, and fracture incidence in the women's health initiative-observational study, J. Bone Miner. Res. 24 (2009) 1369-1379.

[8] C.M. Nielson, P. Srikanth, E.S. Orwoll, Obesity and fracture in men and women: an epidemiologic perspective, J. Bone Miner. Res. 27 (2012) 1-10.

[9] M.A. Bredella, E. Lin, A.V. Gerweck, M.G. Landa, B.J. Thomas, M. Torriani, M.L. Bouxsein, K.K. Miller, Determinants of bone microarchitecture and mechanical properties in obese men, J. Clin. Endocrinol. Metab. 97 (2012) 4115-4122.

[10] A.C. Ng, L.J. Melton III, E.J. Atkinson, S.J. Achenbach, M.F. Holets, J.M. Peterson, S. Khosla, M.T. Drake, Relationship of adiposity to bone volumetric density and microstructure in men and women across the adult lifespan, Bone 55 (2013) 119-125.

[11] W.H. Organization, Physical status: the use and interpretation of anthropometry. Report of a WHO expert committee, World Health Organ. Tech. Rep. Ser. 854 (1995) 1-452.

[12] J.A. Kanis, L.J. Melton III, C. Christiansen, C.C. Johnston, N. Khaltaev, The diagnosis of osteoporosis, J. Bone Miner. Res. 9 (1994) 1137-1141.

[13] S. Cawsey, R. Padwal, A.M. Sharma, X. Wang, S. Li, K. Siminoski, Women with severe obesity and relatively low bone mineral density have increased fracture risk, Osteoporos. Int. 26 (2015) 103-111.

[14] H.M. Frost, The role of changes in mechanical usage set points in the pathogenesis of osteoporosis, J. Bone Miner. Res. 7 (1992) 253-261.

[15] D.T. Felson, Y. Zhang, M.T. Hannan, J.J. Anderson, Effects of weight and body mass index on bone mineral density in men and women: the Framingham study, J. Bone Miner. Res. 8 (1993) 567-573.

[16] I.R. Reid, Relationships among body mass, its components, and bone, Bone 31 (2002) 547-555.

[17] L. Aguirre, N. Napoli, D. Waters, C. Qualls, D.T. Villareal, R. Armamento-Villareal, Increasing adiposity is associated with higher adipokine levels and lower bone mineral density in obese older adults, J. Clin. Endocrinol. Metab. 99 (2014) 3290-3297.

[18] R. El Hage, F. Bachour, W. Khairallah, F. Bedran, N. Maalouf, E. Zakhem, M. Issa, G. Adib, G. Maalouf, The influence of obesity and overweight on hip bone mineral density in Lebanese women, J. Clin. Densitom. 17 (2014) 216-217.

[19] R.E. Hage, F. Bachour, A. Sebaaly, M. Issa, E. Zakhem, G. Maalouf, The influence of weight status on radial bone mineral density in Lebanese women, Calcif. Tissue Int. 94 (2014) 465-467.

[20] M.D. Kontogianni, U.G. Dafni, J.G. Routsias, F.N. Skopouli, Blood leptin and adiponectin as possible mediators of the relation between fat mass and BMD in perimenopausal women, J. Bone Miner. Res. 19 (2004) 546-551.

[21] J.A. Pasco, M.J. Henry, M.A. Kotowicz, G.R. Collier, M.J. Ball, A.M. Ugoni, G.C. Nicholson, Serum leptin levels are associated with bone mass in nonobese women, J. Clin. Endocrinol. Metab. 86 (2001) 1884-1887.

[22] E. Biver, C. Salliot, C. Combescure, L. Gossec, P. Hardouin, I. Legroux-Gerot, B. Cortet, Influence of adipokines and ghrelin on bone mineral density and fracture risk: a systematic review and meta-analysis, J. Clin. Endocrinol. Metab. 96 (2011) 2703-2713.

[23] S.J. Parikh, M. Edelman, G.I. Uwaifo, R.J. Freedman, M. Semega-Janneh, J. Reynolds, J.A. Yanovski, The relationship between obesity and serum 1,25-dihydroxy vitamin D concentrations in healthy adults, J. Clin. Endocrinol. Metab. 89 (2004) 1196-1199.

[24] S. Arunabh, S. Pollack, J. Yeh, J.F. Aloia, Body fat content and 25-hydroxyvitamin D levels in healthy women, J. Clin. Endocrinol. Metab. 88 (2003) 157-161.

[25] A. Cartier, I. Lemieux, N. Almeras, A. Tremblay, J. Bergeron, J.P. Despres, Visceral obesity and plasma glucose-insulin homeostasis: contributions of interleukin-6 and tumor necrosis factor-alpha in men, J. Clin. Endocrinol. Metab. 93 (2008) 1931-1938.

[26] L. Ma, L. Oei, L. Jiang, K. Estrada, H. Chen, Z. Wang, Q. Yu, M.C. Zillikens, X. Gao, F. Rivadeneira, Association between bone mineral density and type 2 diabetes mellitus: a meta-analysis of observational studies, Eur. J. Epidemiol. 27 (2012) 319-332.

[27] L. Oei, M.C. Zillikens, A. Dehghan, G.H. Buitendijk, M.C. Castano-Betancourt, K. Estrada, L. Stolk, E.H. Oei, J.B. van Meurs, J.A. Janssen, A. Hofman, J.P. van Leeuwen, J.C. Witteman, H.A. Pols, A.G. Uitterlinden, C.C. Klaver, O.H. Franco, F. Rivadeneira, High bone mineral density and fracture risk in type 2 diabetes as skeletal complications of inadequate glucose control: the Rotterdam study, Diabetes Care 36 (2013) 1619-1628.

[28] L.J. Zhao, Y.J. Liu, P.Y. Liu, J. Hamilton, R.R. Recker, H.W. Deng, Relationship of obesity with osteoporosis, J. Clin. Endocrinol. Metab. 92 (2007) 1640-1646.

[29] E. Madeira, T.T. Mafort, M. Madeira, E.P. Guedes, R.O. Moreira, L.M. de Mendonca, I.C. Lima, P.R. de Pinho, A.J. Lopes, M.L. Farias, Lean mass as a predictor of bone density and microarchitecture in adult obese individuals with metabolic syndrome, Bone 59 (2014) 89-92.

[30] M.B. Leonard, J. Shults, B.A. Wilson, A.M. Tershakovec, B.S. Zemel, Obesity during childhood and adolescence augments bone mass and bone dimensions, Am. J. Clin. Nutr. 80 (2004) 514-523.

[31] H.A. Weiler, L. Janzen, K. Green, J. Grabowski, M.M. Seshia, K.C. Yuen, Percent body fat and bone mass in healthy Canadian females 10 to 19 years of age, Bone 2 ( 7 ) (2000) 203-207.

[32] M.E. Arlot, E. Sornay-Rendu, P. Garnero, B. Vey-Marty, P.D. Delmas, Apparent preand postmenopausal bone loss evaluated by DXA at different skeletal sites in women: the OFELY cohort, J. Bone Miner. Res. 12 (1997) 683-690.

[33] C. De Laet, J.A. Kanis, A. Oden, H. Johanson, O. Johnell, P. Delmas, J.A. Eisman, H. Kroger, S. Fujiwara, P. Garnero, E.V. McCloskey, D. Mellstrom, L.J. Melton 3rd, P.J. Meunier, H.A. Pols, J. Reeve, A. Silman, A. Tenenhouse, Body mass index as a predictor of fracture risk: a meta-analysis, Osteoporos. Int. 16 (2005) 1330-1338.

[34] M.E. Armstrong, E.A. Spencer, B.J. Cairns, E. Banks, K. Pirie, J. Green, F.L. Wright, G.K. Reeves, V. Beral, Body mass index and physical activity in relation to the incidence of hip fracture in postmenopausal women, J. Bone Miner. Res. 26 (2011) 1330-1338.

[35] J.E. Compston, N.B. Watts, R. Chapurlat, C. Cooper, S. Boonen, S. Greenspan, J. Pfeilschifter, S. Silverman, A. Diez-Perez, R. Lindsay, K.G. Saag, J.C. Netelenbos, 
S. Gehlbach, F.H. Hooven, J. Flahive, J.D. Adachi, M. Rossini, A.Z. Lacroix, C. Roux, P.N. Sambrook, E.S. Siris, Obesity is not protective against fracture in postmenopausal women: GLOW, Am. J. Med. 124 (2011) 1043-1050.

[36] D. Prieto-Alhambra, M.O. Premaor, F. Fina Aviles, E. Hermosilla, D. Martinez-Laguna, C. Carbonell-Abella, X. Nogues, J.E. Compston, A. Diez-Perez, The association between fracture and obesity is site-dependent: a population-based study in postmenopausal women, J. Bone Miner. Res. 27 (2012) 294-300.

[37] K.S. Davison, K. Siminoski, J.D. Adachi, D.A. Hanley, D. Goltzman, A.B. Hodsman, R. Josse, S. Kaiser, W.P. Olszynski, A. Papaioannou, L.G. Ste-Marie, D.L. Kendler, A. Tenenhouse, J.P. Brown, Bone strength: the whole is greater than the sum of its parts, Semin. Arthritis Rheum. 36 (2006) 22-31.
[38] M.L. Bouxsein, P. Szulc, F. Munoz, E. Thrall, E. Sornay-Rendu, P.D. Delmas, Contribution of trochanteric soft tissues to fall force estimates, the factor of risk, and prediction of hip fracture risk, J. Bone Miner. Res. 22 (2007) 825-831.

[39] M.O. Premaor, K. Ensrud, L. Lui, R.A. Parker, J. Cauley, T.A. Hillier, S. Cummings, J.E. Compston, Risk factors for nonvertebral fracture in obese older women, J. Clin. Endocrinol. Metab. 96 (2011) 2414-2421.

[40] E.W. Yu, B.J. Thomas, J.K. Brown, J.S. Finkelstein, Simulated increases in body fat and errors in bone mineral density measurements by DXA and QCT, J. Bone Miner. Res. 27 (2012) 119-124.

[41] N. Binkley, D. Krueger, N. Vallarta-Ast, An overlying fat panniculus affects femur bone mass measurement, J. Clin. Densitom. 6 (2003) 199-204. 